\title{
Editorial for EAIT issue 5, 2021
}

\author{
Arthur Tatnall ${ }^{1}$
}

Accepted: 16 August 2021 / Published online: 20 August 2021

(c) The Author(s), under exclusive licence to Springer Science+Business Media, LLC, part of Springer Nature 2021

Education and Information Technologies (EAIT) is a research journal that covers the complex relationships between Information and Communication Technologies and Education. EAIT is the official journal of the Technical Committee on Education (TC3) of the International Federation for Information Processing (IFIP).

Articles submitted to the journal relate to all levels: the micro level of specific applications or instances of use in classrooms to macro concerns of national policies and major projects; from classes of pre-schoolers to adults in tertiary institutions; from teachers and administrators; to researchers and designers; from institutions to open, distance and lifelong learning. The journal's breadth of coverage allows EAIT to examine fundamental issues at all levels, discuss specific instances and cases, draw inference and probe theory. The journal is embedded in the research and practice of professionals and has been accepted into the Social Science Citation Index (SSCI) in the category 'Education \& Educational Research'. The journal's Impact Factor is 2.917 (2020), and a five-year Impact Factor of 2.953 (2020).

The impact of digital pedagogy training on in-service teachers' attitudes towards digital technologies from Nonmanut Pongsakdi (Chulalongkorn University, Bangkok, Thailand and University of Turku, Finland), Arto Kortelainen (University of Turku, Finland) and Marjaana Veermans (University of Turku, Finland) begins this issue. This study is a part of OpenDigi, which aimed to create teachers' communities for enhancing digital pedagogy skills and the use of digital assessment tools, and to investigate the impact of digital pedagogy training on in-service teachers' attitudes towards digital technologies. The results showed that the impact of the digital pedagogy training depended on teachers' ICT confidence level.

Beyond Bricks and Mortar: The efficacy of online learning and community-building at College Park Academy during the COVID-19 pandemic by Kate Maloney Williams and Anne Corwith (University of Maryland, Maryland, USA) looks at how restrictions due to COVID-19 impacted College Park Academy (CPA), a public charter middle and high school that typically follows a hybrid approach to in-person and online instruction. The purpose of this qualitative study

Arthur Tatnall

Arthur.Tatnall@vu.edu.au

1 Victoria University, Melbourne, Australia 
was to review CPA's transition to full online distance learning during emergency remote teaching. They found that despite strong infrastructure and communications during the transition, there remained issues with school readiness, including the maintenance of academic rigor and social emotional wellbeing.

The next article: The symbiotic relationship between educational robotics and computer science in formal education was contributed by Laila El-Hamamsy (MOBOTS Group, EPFL, Lausanne, Switzerland and Ecole Polytechnique Fédérale de Lausanne, Switzerland), Barbara Bruno (MOBOTS Group, EPFL, Lausanne, Switzerland and Computer-Human Interaction In Learning and Instruction (CHILI) Laboratory, EPFL, Lausanne, Switzerland), Frédérique Chessel-Lazzarotto (Ecole Polytechnique Fédérale de Lausanne, Switzerland), Morgane Chevalier (MOBOTS Group, EPFL, Lausanne, Switzerland and University of Teacher Education, Lausanne, Switzerland), Didier Roy (Ecole Polytechnique Fédérale de Lausanne, Switzerland and Université de Bordeaux, France), Jessica Dehler Zufferey (Ecole Polytechnique Fédérale de Lausanne, Switzerland) and Francesco Mondada (MOBOTS Group, EPFL, Lausanne, Switzerland). They begin by pointing out that Educational Robotics (ER) has the potential to provide significant benefits to education, providing an increase in outreach by transitioning from the extra-curricular initiatives in which ER has thrived to formal education. As Computer Science Education is undergoing curricular reforms worldwide, this study addresses the case of a Digital Education reform that included ER to teach core CS concepts.

Ünal Çakıroğlu, Merve Aydın, Adem Özkan, Şeyma Turan and Aslı Cihan (Trabzon University, Sögüutlü, Akçaabat, Turkey) then offer: Perceived learning in virtual reality and animation-based learning environments: A case of the understanding our body topic. This paper reports on a study aiming at examining the effects of virtual reality and animations on students' perceived learning. It was conducted as an exploratory case study in virtual reality-based and animation-based environments. While immersion was found as a positive feature that is robust in a virtual realitybased environment, limited interactivity somewhat negatively influenced perceived learning in animation-based learning environment. While a virtual reality-based learning environment provided high student-content interaction, surprisingly this caused some unrealistic perceptions of students about their own learning.

Cultivating key competencies contributes to students' adaptation to the fast developing intelligent era says Xiaodong Huang (Capital Normal University, Beijing, China) in the article: Aims for cultivating students' key competencies based on artificial intelligence education in China. Artificial intelligence (AI) education is an important way to cultivate students' key competencies, the author argues. It is seen as increasingly important to set up appropriate artificial intelligence courses at the fundamental education stage and cultivate students' key competencies via such courses, and this paper quantitatively describes how AI courses cultivate students' key competencies.

Self-directed learning with knowledge management model on academic achievement and digital literacy abilities for employees of a Thai energy organization is by Aime-acha Silamut and Thanongsak Sovajassatakul (King Mongkut's Institute of Technology Ladkrabang, Bangkok, Thailand). In a previous paper they described a self-directed learning with knowledge management (SDLKM) model to 
motivate learners in an organisation to learn from internal-and-external knowledge management resources to enhance their Academic Achievement and Digital Literacy Abilities. In this paper, they demonstrate the value of this model by comparing these abilities in a controlled experiment with employees of an energy regulatory organisation in Bangkok, Thailand.

Mustafa Kamel Mohammadi (Bamyan University, Afghanistan), Abdul Aziz Mohibbi and Mohammad Hadi Hedayati (Kabul University, Afghanistan) then present: Investigating the challenges and factors influencing the use of the learning management system during the Covid-19 pandemic in Afghanistan. They point out that successful implementation and use of learning management systems (LMSs) have become a critical challenge for many higher education institutes during the COVID-19 pandemic and although LMSs with lots of features were developed for universities, the success of these systems is highly related to a detailed understanding of challenges and factors influencing the use of the systems among their users. HELMS (Higher Education Learning Management System) is a countrywide LMS used for teaching and learning during the quarantine period caused by Covid19 in Afghanistan universities. This research investigates the challenges that face the use of HELMS and explores the factors influencing the use of HELMS among both lecturers and students.

Factors influencing E-learning adoption in India: Learners' perspective by P.S. Vanitha and Sreejith Alathur (National Institute of Technology, Karnataka, India) argue that in the era of electronic-learning 3.0, existing dimensions related to technologies and learners are not adequately explored while discussing e-learning adoption. In this study technology and learner dimensions are converged to overcome this insufficiency in analysing e-learning adoption. The study identifies technology and learner dimension factors that influence e-learning adoption in developing countries like India.

The Learning Path Adaptation problem (LPA) is one of the most challenging problems within the field of adaptive learning and is also a well-known combinatorial optimisation problem, its main target being the knowledge resources sequencing offered to a specific learner with a specific context say Ouissem Benmesbah, Mahnane Lamia and Mohamed Hafidi (Badji Mokhtar University, Annaba, Algeria) in: An enhanced genetic algorithm for solving learning path adaptation problem. This paper summarizes existing works and presents an innovative approach modelled as an objective optimization problem, and an improved Genetic algorithm (GA) is proposed to deal with it.

Ali Azeez Al-Jumaili (University of Baghdad College of Pharmacy, Iraq and University of Iowa College of Pharmacy, USA), Kawther K. Ahmed (University of Baghdad College of Pharmacy, Iraq and University of Iowa College of Pharmacy, USA), Ahmed Kadhim Al-Jalehawi (University of Al Kafeel College of Pharmacy, Al-Najaf, Iraq), Bashar G. Al-Fatlawi (University College of Pharmacy, Al-Qādisiyyah, Iraq), Mohammed D. Al-Rekabi (University of AlKafeel College of Pharmacy, Al-Najaf, Iraq) and Oday Sajjad Al-Sawad (University of Basra College of Pharmacy, Basra, Iraq) and Falah Hasan Shari (University of Basra College of Pharmacy, Basra, Iraq) then present: Evaluating the use of informational technologies by students of healthcare colleges for academic 
purposes over a five-year period. Their study aimed to assess the extent to which healthcare students use five informational technologies: electronic course management, internet, computer, audio recording/commentary, and PowerPoint slides, for daily academic purposes and to examine the changes in student perceptions toward these technologies over five years.

Effects of teaching a computer programming language via hybrid interface on anxiety, cognitive load level and achievement of high school students investigates the effects of teaching Python programming language via Blockly tool, which had hybrid interface, on students' computer programming anxiety, cognitive load level, and achievement. It describes research by: Alper Unal (Teacher in Ministry of National Education, Antalya, Turkey) and Fatma Burcu Topu (Ataturk University, Erzurum, Turkey). Participants were high school students, in an experimental group (hybrid interface) and control group (non-hybrid interface). According to results, there was a meaningful difference between programming achievement scores of students in favour of the experimental group (hybrid interface) while there was no difference in terms of computer programming anxiety between groups.

Solomon Sunday Oyelere (Luleå University of Technology, Sweden), Sunday Adewale Olaleye (University of Oulu, Finland), Oluwafemi Samson Balogun (University of Eastern Finland, Kuopio, Finland) and Łukasz Tomczyk (Pedagogical University of Cracow, Poland) then offer: Do teamwork experience and self-regulated learning determine the performance of students in an online educational technology course? Their study used a quantitative research approach to examine the connection between students' teamwork experience, self-regulated learning, technology self-efficacy, and performance in an online educational technology course. Right self-regulated learning strategies in online courses motivate students to strive for a good teamwork experience, leading to increased interest in online learning. In addition, the results also show that there is a relationship between satisfaction and the level of the online course.

The primary aim of the study by Şefika Sümeyye Çam (Muş Alparslan University, Muş, Turkey) and Gürcü Erdamar Koç (Gazi University, Ankara, Turkey): A needs analysis study on technological pedagogical content knowledge of faculty members was to determine the current state in education faculties and faculty members' needs for a professional training program that would be prepared for their TPACK development. Their results showed that faculty members perceived themselves incompetent in terms of TPACK because they thought they had limited knowledge of technology. Although they emphasised that they had sufficient pedagogical knowledge, they were found to use mainly teacher-centred instructional methods by means of PowerPoint presentations.

Preparing pre-service teachers to integrate teaching technologies into their classrooms: Examining the effects of teaching environments based on open-ended, hands-on and authentic tasks describes research by Hatice Yildiz Durak (Bartin University, Turkey). The author says that pre-service training is the most important stage when teachers learn about integrating technology into their teaching and that pre-service teachers' perceptions of the effectiveness of technologies can be used to predict their intention of including technology in their classrooms in the future. 
The purpose of this study was to determine whether the different methods effect teachers' technology integration self-efficacy (TISE), motivation, satisfaction, and attitude towards the use of technology.

Viet Anh Nguyen, Hoa-Huy Nguyen, Duc-Loc Nguyen and Minh-Duc Le (Vietnam National University Hanoi, Vietnam) then offer: A course recommendation model for students based on learning outcome. Choosing the most appropriate courses to study throughout the learning process remains a question many students are interested in. Students often choose suitable courses according to their interests, needs, and advice from supporting staff. This paper presents the results in developing a course recommendation system that will select appropriate courses for each student studying a major in the following semesters based on their academic performance.

The next article reports on a study to identify and distinguish different needs of primary school teachers for e-courseware that are used to support the teaching process. Expectations of primary school teachers on e-courseware support teaching: An evidence from Vietnam comes from Quoc Hoa Tran-Duong (Dong Nai University, Bien Hoa City, Dong Nai, Vietnam). Even though there has been strong growth in e-courseware for primary schools, teachers do not pay attention and use it as expected, says the author. There is a need to investigate what teachers expect from e-courseware before developing it in order that this e-courseware will not be neglected by teachers.

Hicham EL MRABET and Abdelaziz AIT MOUSSA (Mohammed I University, Oujda, Morocco) then offer: IoT-school guidance: A holistic approach to vocational self-awareness \& career path, pointing out that schools are responsible for helping students in their vocational career development in the sense that they should sustain students in developing skills required by the job market. This study developed a school guidance system called "IoT-School Guidance" to create a smart and conducive environment for the successful adoption of school guidance using the Internet of things (IoT). This new approach includes implementing an adaptive orientation process using smart technologies to guide pre-tertiary students to choose and follow the best professional career generated automatically by the IoT-school guidance system.

Information society and its impact on personality development describes a study by Olga Garanina (Moscow State Technical University of Civil Aviation, Russia), Nidal Al Said (Ajman University, Ajman, United Arab Emirates), Valery Stepenko (Pacific State University, Khabarovsk, Russia) and Marija Troyanskaya (Orenburg State University, Orenburg, Russia) to develop and test an original model which illustrates the development of personality in the information society. The model described in the study is relevant in the context of the transfer of the educational process in higher education to a distance format and the growing social isolation of an individual caused by the coronavirus pandemic.

As computational thinking (CT) gains more attention in K-16 education, problemsolving has been more emphasized as a core competency that can be found across various domains, say Kyungbin Kwon (Indiana University, Bloomington, USA), Jongpil Cheon (Texas Tech University, Lubbock, USA) and Hyunchang Moon (Texas Tech University, Lubbock, USA) in their article: Levels of problem-solving 
competency identified through Bebras Computing Challenge. To develop an evaluation framework that reveals students' problem-solving competency, this study examined solutions for the Bebras Computing Challenge which requires students to utilize problem-solving skills in a CT domain. This study presented solution levels across Bebras tasks and discussed how task difficulty affected student solutions differently. Implications for teaching problem-solving skills are discussed.

Learning management systems and technology acceptance models: A systematic review by Maryam N. Al-Nuaimi (Al Buraimi University College, Oman) and Mostafa Al-Emran (The British University in Dubai, United Arab Emirates) begins by stating that technology acceptance has become one of the dominant research fields in the domain of learning management systems (LMSs), but that there is still little or no holistic review and taxonomy of studies in this field. The main objective of the reported research was toward understanding the most prevalent theoretical models and the most prominent external factors affecting the LMS adoption in higher educational institutions. The results indicated that TAM, DeLone and McLean IS success model, UTAUT, TRA, DOI, and UTAUT2 have dominated the theoretical landscape in LMS research.

Contextualized game-based intervention for digital literacy for the Pacific Islands is from Pritika Reddy (Fiji National University, Suva, Fifi), Kaylash Chaudhary, Bibhya Sharma and Darren Chand (The University of the South Pacific, Suva, Fiji). This research paper articulates design details, validity, reliability, and effectiveness of a new online modulated digital literacy intervention program (DLIP). For the development of DLIP, digital literacy is stipulated in this research as a universal framework that consists of six different literacies: media, information, technology, computer, visual, and communication literacy. An online module was designed for each of these six literacies, and the concept of game-based learning used to engage the users and secure high user satisfaction.

Katerina Tzafilkou, Maria A. Perifanou, Anastasios A. Economides from SMILE Lab, University of Macedonia, Thessaloniki, Greece) then present Teachers' trainers' intention and motivation to transfer ICT training: The role of ICT individual factors, gender, and ICT self-efficacy. Most previous studies have investigated the transfer of ICT training and its application in the daily teaching practice by ordinary teachers, often neglecting the important group of teacher trainers, who receive advanced ICT training before starting to train their colleagues. The main purpose of this study was thus to investigate the teacher trainers transfer of ICT training analysing the structural relationships of variables with their gender, ICT self-efficacy, and a set of ICT individual factors.

Husam A. Qaddumi (Al Istiqlal University, Jericho, Palestine) then reports on a quasi-experimental study exploring the impact of Edmodo on students' achievement in language skills and retention in an EFL context: $\boldsymbol{A}$ study on the impact of using Edmodo on students' achievement in English language skills and retention. The study compared experimental groups, taught with the help of Edmodo, and control groups. Results suggested significant differences in students' language skills acquisition and retention in favour of the experimental group.

Does the student's perspective on multimodal literacy influence their behavioural intention to use collaborative computer-based learning? 
Dokun Oluwajana and Ibrahim Adeshola (Eastern Mediterranean University, Famagusta, North Cyprus) investigate this. They propose a theoretical model that examines student perspectives on the integration of digital multi-modal literacy in the Unified Theory of Acceptance and Use of Technology (UTAUT) model. The study empirically examined and validated the proposed theoretical model based on a digital multimodal computer-supported collaborative learning adoption.

Novel online video model for learning information technology based on micro learning and multimedia micro content by Ricardo Gerbaudo, Ricardo Gaspar and Romulo Goncalves Lins (Federal University of ABC, Santo André, Brazil) proposes a novel online video model to be used in the continuing education of IT professionals. A five-stage process, composed of empathy, definition, ideation, prototype, and tests, has been adopted according to the Design Thinking methodology. All stages were focused on knowing the users' needs and creating the video format that satisfies their expectations.

The next paper investigates the use of dashboards and data visualizations as a teaching tool in accounting units. Using dashboards and data visualizations in teaching accounting by Maria Prokofieva (Victoria University, Melbourne, Australia) notes that accounting has a growing demand for data analytics and visualization but that graduates often lack understanding and skills in this area. The paper addresses this gap by introducing dashboards and data visualizations in teaching accounting units. Approaching visualization as a cognitive tool, the study develops a model aligning conceptual blocks in the accounting domain with the dashboard visualization environment. The paper suggests directions on implementation of visualization in accounting reporting and accounting education and provides recommendations for researchers in those areas.

Advances in technology present multiple modes by which parents and teachers can now communicate, say Tingting Xu, Adam Akerson and Brandon Fox (Austin State University, Nacogdoches, USA) in their article: Incorporating technology to foster effective communication and documentation in child-care programs. Their article examines a new approach that a child-care program adopted to document and share daily activities of individual children, including their development, while making this information accessible to the child's parents, using a Childcare Management Software (CMS) mobile application.

Competence representation and the use of educational technology support for Thai learners was contributed by Athitaya Nitchot (Prince of Songkla University, Hatyai, Thailand), Lester Gilbert (University of Southampton, UK) and Wiphada Wettayaprasit (Prince of Songkla University, Hatyai, Thailand). They note than in Thailand, ICT has been adopted for learning and teaching within higher education, where ClassStart, Moodle, and Learn Square have been commonly used. In their research, a conceptual model of competence is proposed as a learner's capability with respect to subject matter, and based on this model a tool is implemented called "Mytelemap" which supports linking web resources to subject matter, interactive visualization and creation of subject matter and competence maps, and identification of learning paths on the maps.

Maria Chiara Pino (University of L'Aquila, Italy and Regional Reference Centre for Autism of the Abruzzo Region, L’Aquila, Italy), Roberto Vagnetti 
(University of L'Aquila, Italy), Marco Valenti and Monica Mazza (University of L'Aquila, Italy and Regional Reference Centre for Autism of the Abruzzo Region, L'Aquila, Italy) then offer: Comparing virtual vs real faces expressing emotions in children with autism: An eye-tracking study. Difficulties in processing emotional facial expressions is considered a central characteristic of children with autism spectrum condition (ASC). There is a growing interest in the use of virtual avatars capable of expressing emotions as an intervention aimed at improving the social skills of these individuals. The aim of the reported study was to assess differences in eye gaze processes in children with ASC when they see avatar faces expressing emotions compared to real faces.

Teaching Machine Learning in school helps students to be better prepared for a society rapidly changing due to the impact of Artificial Intelligence, but this requires age-appropriate tools that allow students to develop a comprehensive understanding of Machine Learning (ML) to become creators of smart solutions. Christiane Gresse von Wangenheim (Federal University of Santa Catarina, Florianópolis, Brazil), Fernando S. Pacheco (Federal Institute of Santa Catarina, Florianópolis, Brazil), Jean C. R. Hauck and Matheus F. Bertonceli Bueno (Federal University of Santa Catarina, Florianópolis, Brazil) propose this in their article: Visual tools for teaching machine learning in K-12: A ten-year systematic mapping. Following the trend of visual languages for introducing algorithms and programming in K-12, they present a ten-year systematic mapping of emerging visual tools that support the teaching of Machine Learning at this educational stage and analyse the tools concerning their educational characteristics, support for the development of ML models as well as their deployment and how the tools have been developed and evaluated.

Blockchain adoption in education: a systematic literature review. Faiza Loukil (Univ. Polytechnique Hauts-de-France, Valenciennes, France), Mourad Abed (Univ. Polytechnique Hauts-de-France, Valenciennes, France and INSA Hauts-de-France, Valenciennes, France) and Khouloud Boukadi (Sfax University, Tunisie) point out that the rapid development of blockchain technology has influenced several fields, including financial, healthcare, and supply chain systems, and recently, this technology has also been applied in education thanks to its unique features, including decentralization, trustworthiness, and security. Despite this aspect of blockchain, several concerns continue to undermine its adoption in education, such as legal, immutability, and scalability issues. This paper is a systematic literature review of blockchain applications in the education field, focusing on educational applications and benefits of blockchain integration.

This next paper analyses how learners interact with the pedagogical sequences of educational videos, and its effect on their performance: Predicting learner's performance through video sequences viewing behaviour analysis using educational data mining. It comes from Houssam El Aouifi (IRF-SIC Laboratory, Ibn Zohr University, Agadir, Morocco), Mohamed El Hajji (IRF-SIC Laboratory, Ibn Zohr University, Agadir, Morocco and CRMEF-SM, Agadir, Morocco), Youssef Es-Saady and HassanDouzi (IRF-SIC Laboratory, Ibn Zohr University, Agadir, Morocco). In their study they focus on the interpretation of the path followed by a learner 
watching an educational video, and the way they navigate the pedagogical sequences of that video, to predict whether a learner can pass or fail the video course.

Co-design of mini games for learning computational thinking in an online environment is from Friday Joseph Agbo (University of Eastern Finland), Teemu H. Laine (Ajou University, Republic of Korea), Solomon Sunday Oyelere (Luleå University of Technology, Sweden) and Jarkko Suhonen (University of Eastern Finland). Understanding the principles of computational thinking (CT) is vital for computer science students, but unfortunately these concepts can be difficult for novice students to understand. One way that students can develop CT skills is to involve them in the design of an application to teach CT. This study focuses on codesigning mini games to support teaching and learning CT principles and concepts in an online environment.

Can we do better? a classification of algorithm run-time-complexity improvement using the SOLO taxonomy by Lior Aronshtam, Tammar Shrot and Ronit Shmallo (Shamoon College of Engineering, Ashdod, Israel) begins by stating that improving code while preserving its functionality is a common task in the hi-tech industry, but that students have difficulties improving an algorithm's runtime complexity by an order of magnitude. The paper focuses on assessing students' abilities in this area. It presents a novel SOLO taxonomic levels for tasks improving run-time complexity and offers several suggestions to assist students and enhance the teaching process.

The purpose of the next study was to examine the effect of a new vocabulary revision technique "peer-chain" developed by the researchers on vocabulary learning and retention among English as a Foreign Language (EFL) university students. A new vocabulary revision technique using WhatsApp: Peer-chain comes from Özgül Balcı and Galip Kartal (Necmettin Erbakan University, Konya, Turkey). The study showed a significant difference in students' vocabulary achievement between the students who used peer-chain and the students who used traditional word cards. The research suggested that integrating WhatsApp with the peer-chain technique in teaching vocabulary is a promising technique and can be more successful than the traditional paper-based word cards for vocabulary learning and retention.

Shwetha Sridharan, Deepti Saravanan, Akshaya Kesarimangalam Srinivasan and-Brindha Murugan (National Institute Technology, Tiruchirappalli, Tamil Nadu, India) next write on: Adaptive learning management expert system with evolving knowledge base and enhanced learnability. This paper develops an adaptive learning management system to tackle the challenge that every learner differs in terms of their learning speed, proficiency, and preferred mode of learning. The system creates a customized course for every student based on their level of knowledge, preferred mode of learning and continuously updates the course based on their learning speed. The material is filtered from a knowledge base that is dynamically updated using web scraping and ranked using feedback from students on the relevance and quality of each material.

The effect of perceived competence on second language communication frequency: the mediating roles of motivation, willingness to communicate, and international posture by Shima Balouchi and Arshad Abdul Samad (Universiti Putra Malaysia, Selangor, Malaysia) describes a study to investigate the mediating effects 
of second language (L2) motivation, willingness to communicate (WTC), and international posture on the relationship between L2 self-perceived communication competence (SPCC) and L2 frequency of communication (L2 FC) in online informal English learning contexts among tertiary students in Malaysia. The findings suggested that a higher level of L2 SPCC would lead to more frequent L2 use in online contexts.

Using process mining for Git log analysis of projects in a software development course is from Martin Macak, Daniela Kruzelova, Stanislav Chren and Barbora Buhnova (Masaryk University, Brno, Czech Republic). Understanding the processes in education, such as the student learning behaviour within a specific course, is a key to continuous course improvement, they note. In online learning systems, students' learning can be tracked and examined based on data collected by the systems themselves, but it is non-trivial to decide how to extract the desired students' behaviour from the limited data in traditional classroom courses. In this paper, they propose process mining for improvement-motivated process analysis of a software development course (web development in particular) and analyses Git logs of students' projects to understand their development processes. The main contribution of this paper is the detailed methodology of process mining usage for students' project development analysis, considering various commit characteristics, which are crucial in understanding student coding behaviour patterns.

Career development is a multifaceted, life-stage-dependant and discipline-specific process that is difference for every decision maker. During their time at university, students are building upon their career choice through discipline-specific activities yet many still find the transition into the workforce problematic, particularly for those in the discipline of IT. This paper demonstrates how a career development model together with appropriate curriculum resources can assist in addressing students' career needs, specifically for the IT context. Integrating career development into an undergraduate IT curriculum at an Australian University was presented by Sophie McKenzie and Jo Coldwell-Neilson (Deakin University, Geelong, Australia) and Stuart Palmer (Australia WorkSafe Victoria, Geelong, Australia). This research asked: What career development model, and curriculum recommendations, can support IT students to be better prepared for life after university to achieve their graduate outcomes?

Vo Ngoc Hoi (Quy Nhon University, Vietnam and Ho Chi Minh City Open University, Vietnam) and Ho Le Hang (Ho Chi Minh City Open University, Vietnam) next offer: Understanding students' behavioural intention to use Facebook as a supplementary learning platform: A mixed methods approach. Research and practice in the use of social networks for educational purposes have indicated the potential of Facebook as an online supplementary learning platform, but empirical evidence regarding students' perception and acceptance of Facebook remains limited. This study adopts an exploratory sequential mixed methods design to understand factors that affect students' intention to use Facebook as a course-based online supplementary learning platform, and the mechanisms through which these effects are exerted.

Advancement in virtual reality (VR) technology has enabled language learners to be engaged in immersive and interactive learning environments say Mengyuan Chen, 
Ching-Sing Chai, Morris Siu-Yung Jong and Grace Chih-Nuo Chao (The Chinese University of Hong Kong, China) in their article: Modelling learners' self-concept in Chinese descriptive writing based on the affordances of a virtual reality-supported environment. In their study, adopting the self-determination theory as the theoretical lens, the affordances of VR contributing to students' self-concept in descriptive writing were explored through a newly adapted survey. The results indicated self-efficacy and satisfaction directly predict students' writing self-concept, and relatedness indirectly predicts writing self-concept.

The evaluation of chatbot as a tool for health literacy education among undergraduate students reports on research by Nur Azlina Mohamed Mokmin and Nurul Anwar Ibrahim (Universiti Sains Malaysia, Penang, Malaysia). This study discusses and evaluates the usefulness, performance, and technology acceptance of a chatbot developed to educate users and provide health literacy. Each respondent explored the health chatbot actively to get advice from it with a phrase that matched the chatbot's intents via mobile devices. An overall assessment showed that the developed chatbot has a significant potential to be used as a conversational agent to increase health literacy, especially among students and young adults.

Mining educational data to predict students' performance: A comparative study of datamining techniques by Khaledun Nahar, Boishakhe Islam Shova, Tahmina Ria, Humayara Binte Rashid and A.H.M. Saiful Islam (Notre Dame University Bangladesh, Dhaka, Bangladesh) note that information everywhere is hidden and scattered and becomes useful when we apply data mining to extracts the hidden, meaningful, and potentially useful patterns from these vast data resources. Educational data mining ensures a quality education by analysing educational data based on various aspects. In this paper, they analysed the academic results and behaviour of some engineering students, their main goal being to predict the students' performance.

Chrysoula Kroustalli and Stelios Xinogalos (University of Macedonia, Thessaloniki, Greece) then present: Studying the effects of teaching programming to lower secondary school students with a serious game: a case study with Python and CodeCombat. Serious games, or educational games for programming are considered to have a positive impact on learning programming as they motivate students and engage them in playing and learning programming, the authors argue. In this study the effects of teaching programming to lower secondary school students with the serious game CodeCombat and the typical teaching approach are compared. Students formed an experimental group that was taught programming with CodeCombat and a control group that was taught programming through lecturing and problem solving in Python with a typical programming environment. The results were neutral in terms of students' behavioural intention to use CodeCombat but were positive in using serious games for programming in general.

The next study analysed whether the self-evaluation of online teaching effectiveness (SEOTE) and literacy of learning manage system (LLMS) did significantly have effect on the level of self-directed learning readiness (SDLR). The mediating effect of literacy of LMS between self-evaluation online teaching effectiveness and self-directed learning readiness comes from JeongChul Heo (Sehan University, Chungnam, Korea) and Sumi Han (Seoul Cyber University, Korea). This 
study included online college students in Korea who responded to three web survey questionnaires (SEOTE, LLMS, and SDLR) and the results of mediated regression analysis revealed that LLMS did have a significant indirect or mediating effect with SEOTE in predicting SDLR.

Research ethics dilemma in higher education: Impact of internet access, ethical controls, and teaching factors on student plagiarism by Asad Abbas (Tecnologico de Monterrey, Mexico), Anam Fatima (University of Science and Technology of China), Arturo Arrona-Palacios (Tecnologico de Monterrey, Mexico), Hussein Haruna (University of Hong Kong) and Samira Hosseini (Tecnologico de Monterrey, Mexico and Tecnologico de Monterrey, Mexico) explores the external factors of plagiarism among university students in Pakistan. Data were collected from Islamabad city-based university students using an on-line survey that contains questions related to students' plagiarism, from internet access, ethical control, and teaching factors. The findings imply that culture and personal factors have a role in strict implementation of rules and creating awareness on the importance of preventing student's involvement in plagiarism.

Ahmad Zamzuri Mohamad Ali (Universiti Pendidikan Sultan Idris, Malaysia) and Mohd Khairulnizam Ramlie (Universiti Teknologi Mara, Perak, Malaysia) then write on: Examining the user experience of learning with a hologram tutor in the form of a 3D cartoon character. A hologram tutor is an instructional medium that has promising potential to serve as a substitute for actual teachers in classroom learning, they say. The purpose of this research was to design and develop a 3D cartoon-like hologram tutor and examine aspects of the user experience (UX). Their results suggested that the UX level with a $3 \mathrm{D}$ cartoon-like hologram tutor was promising and positive.

The case study that follows, from Meina Zhu, Sarah Berri and Ke Zhang (Wayne State University, Detroit, USA), explored effective instructional strategies and technology use in blended learning (BL) in a graduate course in the USA: Effective instructional strategies and technology use in blended learning: A case study. These were identified in BL. The findings indicated that students valued real-time interactions with peers and the instructor, but inappropriate asynchronous discussions were considered less effective. In addition, immediate feedback from peers and the instructor motivated learners and improved the quality of their work.

The purpose of the next study was to analyse the factors that influence university students' acceptance of mobile learning. University students' acceptance of mobile learning: A comparative study in Turkey and Kyrgyzstan is by Gülgün Afacan Adanır (Ankara University, Ankara, Turkey) and Gulshat Muhametjanova (Kyrgyz-Turkish Manas University, Bishkek, Kyrgyz Republic). The effectiveness of mobile learning depends on student acceptance and this study used the Technology Acceptance Model (TAM) and Theory of Planned Behaviour (TPB) to look at attitude, subjective norm, and perceived behavioural control as the major antecedents of students' behavioural intention to use mobile learning. Turkish and Kyrgyz students showed both similarities and differences in the effects of factors on mobile learning use.

Research on mobile learning in a teaching information service system based on a big data driven environment by Jia Qu (Chengde Petroleum College, China) 
looks at the challenges of mobile learning in the big data environment and the current research status of teaching intelligent services. The article explores the construction of mobile learning in the teaching intelligent service system of colleges and universities from a big data driven perspective, and also the business process of mobile learning for support and guidance from which big-data-driven mobile learning intelligent service framework system is constructed.

The following article: Implementing theoretical approaches using ICT in teaching English as a foreign language is by Evangelia Tzagkourni, Elissavet Chlapana and Nicholas Zaranis (University of Crete, Greece). The purpose of this study was to explore the effect of an instructional approach that utilizes ICT and is based on Van Hiele's levels of geometric thought and Hoffer's skills that describe them, for the instruction of the English Alphabet. The research sample consisted of Greek students attending the second grade of primary school, divided into two groups: control and experimental. The former was taught according to the curriculum provided by the Greek Ministry of Education and Religious Affairs, while the experimental group was taught through an intervention based on the principles of Blended Learning. The results of the study showed that the intervention had a significant effect on students' learning English alphabet letters.

Students' engagement in E-learning applications is considered an important factor for learning says Jehad Imlawi (Al al-Bayt University, Mafraq, Jordan), and there is evidence in the literature on their learning outcomes and achievement. Sound utilisation in E-learning applications is expected to influence the students' engagement in such applications. This is described in the article: Students' engagement in E-learning applications: The impact of sound's elements. The reported study adopted the arousal theory, to check whether adding sound's elements (voiceovers, background music and sound effects) to the E-learning applications would improve the students' engagement in such applications. The results showed that the sound's elements, especially voiceovers, positively influence the students' engagement, when controlling for students' age, gender, and their prior experience with E-learning applications.

Chatbot application in $\mathbf{a} \mathbf{5}^{\text {th }}$ grade science course by Arzu Deveci Topal, Canan Dilek Eren and Aynur Kolburan Geçer (Kocaeli University, İzmit, Kocaeli, Turkey) investigates the effect of chatbots, that work with artificial intelligence, on the success of students and their opinions about chatbots in the 'Matter and the changing state of matter' unit in the $5^{\text {th }}$ grade science course. In addition to text-based functions, the designed chatbot includes a video accessed on the web to support students visually and aurally. Students' opinions about the chatbot included that it was useful and fun, they would like to use it for other courses, it provided useful assistance in learning outside the classroom, and it allowed them to repeat the course again.

The education system has been radically transformed by technological impetuses owed to the Fourth Industrial Revolution point out Jonela Carmada Marisa Wilson (Dongbei University of Finance and Economics, Dalian, China), Patrick Kandege (Dalian University of Technology, Dalian, China), Akadje Jean Roland Edjoukou (Dongbei University of Finance and Economics, Dalian, China) and Mussie Tesfay Teklu (Dongbei University of Finance and Economics, Dalian, China) in their article: Unpacking smart education's soft smartness variables: Leadership and 
human resources capacities as key participatory actors. Developing nations are currently expedited smart education implementation to combat the negative effects COVID19 has on education. This presents managerial issues. A review of the literature on smart education shows that past studies focused primarily on the smart learning environment, substantially ignoring the importance of leadership and human resource capacity in the management of smart education. This study addresses this deficiency as it relates to the key factors that enable success in the management of smart education.

The differential relationships between PISA 2015 science performance and, ICT availability, ICT use and attitudes toward ICT across regions: evidence from 35 countries was contributed by Sümeyye Arpacı (Columbia University, New York, USA), Fatih Çağlayan Mercan and Serkan Arıkan (Boğaziçi University, Istanbul, Turkey). Before 2015, the PISA tests were paper based, but in 2015, for the first time, a computer-based test was used, and the mean score in science performance decreased dramatically. To propose a plausible reason for this decrease, the relationships between students' science performance and students' ICT availability, ICT use, and attitudes toward ICT were examined. The results indicated that there was a differential relationship among countries and regions for how much of the total variance was explained through ICT related factors.

Academic use of social networking sites in learners' engagement in underdeveloped countries schools: Afzal Badshah (International Islamic University, Islamabad, Pakistan), Ateeqa Jalal (University of Science \& Technology, Bannu, Pakistan), Ghani Ur Rehman and Muhammad Zubair (Khushal Khan Khattak University, Karak, Pakistan) and Muhammad Muneer Umar (Kohat University of Science and Technology, Pakistan). With the recent advances in ICT such as the Internet of Things, Artificial Intelligence and 5G, there is a need to revive smart use in academia. In underdeveloped countries, parents have financial burdens and educating children is not a priority. This results in students not being effectively engaged in learning. This study investigated the role of social media in learners' engagement by making a productive relationship among the parents, teachers, and Principals in underdeveloped countries' schools.

Zhanni Luo, Cheryl Brown and Billy O'Steen (University of Canterbury, Christchurch, New Zealand) then offer: Factors contributing to teachers' acceptance intention of gamified learning tools in secondary schools: An exploratory study. Gamified learning tools refer to the websites, software or mobile applications that use game design elements for educational purposes and although theoretically promising in engaging leaners, gamified learning tools were not widely accepted in practice. This paper seeks to better understand what encourages and constrains teachers' use of gamified learning tools in secondary schools in China to better realise the potential of gamification in formal learning contexts.

Next is a correction to the previously published article: Preparing student teachers for real classrooms through virtual vicarious experiences of critical incidents during remote practicum: A meaningful experiential learning perspective by Saadet Korucu-Kış (Necmettin Erbakan University, Konya, Turkey).

Student's profile modelling in an adaptive gamified learning environment by Siwar Missaoui (University of Sousse, Tunisia), Ahmed Maalel (University of 
Sousse, Tunisia and University of Manouba, Tunisia) points out that a student's profile, comprising information on student's characteristics such as background knowledge, learning style preference, goals, and personality, defines the best way a student chooses to learn. The foremost challenge that the students experience in learning systems is that they are unable to bring back relevant information based on their needs. The reported research consisted in modelling a student's profile based on many important characteristics.

The next study is based on a teaching-module designed to introduce computational thinking (CT) to pre-service teachers pursuing MA degrees at a large-scale university in Ankara, Turkey that aims to explore Turkish pre-service teachers' perceptions and integration of CT in different disciplines through CT-based tasks: Demystifying computational thinking for teacher candidates: A case study on Turkish secondary school pre-service teachers and come from Armağan Ateşkan (Bilkent University, Ankara, Turkey) and Deniz Ortactepe Hart (Middlebury Institute of International Studies at Monterey, USA). Student lesson plans were analysed to explore the challenges they faced while integrating CT into their teaching.

Transitioning to E-Learning during the COVID-19 pandemic: How have Higher Education Institutions responded to the challenge? Darren Turnbull, Ritesh Chugh and Jo Luck (Central Queensland University, Australia) remark that lockdowns, social distancing, and COVID safe hygiene practices have rendered the usual face-to-face course delivery options all but impossible for many higher education institutions worldwide, making a forced transition to online learning the only viable option for preventing a wholesale closure of many institutions. This paper identified five challenges to transitioning to online education experienced by higher education institutions: synchronous/asynchronous learning tool integration, access to technology, faculty and student online competence, academic dishonesty, and privacy and confidentiality.

The COVID-19 pandemic has provided students more opportunities to learn and improve themselves at their own pace say Aditya Nigam, Rhitvik Pasricha, Tarishi Singh and Prathamesh Churi (NMIMS University, Mumbai, India) in their article: A Systematic Review on AI-based Proctoring Systems: Past, Present and Future. Online proctoring services (OPS), which make use of online tools to maintain the sanctity of an examination, and AI-based proctoring systems (AIPS) are on the rise. While most of this software uses various modules, the sensitive information they collect raises concerns among the student community. This paper reviews existing $\mathrm{AI}$ and non-AI-based proctoring systems. The conclusion they reach is that the ethical justification of these technologies and their various capabilities requires us to rigorously ensure that a balance is struck between the concerns with the possible benefits to the best of our abilities.

The following article: Constituent of information governance framework for a successful implementation in Nigerian Universities was offered by Jika Saidu Muhammad, Azman Mat Isa and Ahmad Zam Hariro Shamsuddin (Universiti Teknologi MARA Selangor Branch, Malaysia) and Shah Jahan Miah (Newcastle Business School, NSW, Australia). Its purpose was to investigate the possible content of IG (Information Governance) framework for implementation in Nigerian 
universities, and to identify important areas when planning for the framework to provide better information management in the universities. Their findings suggest that IG implementation could alleviate enormous challenges of records and information management in the universities.

Surattana Adipat (Ramkhamhaeng University, Bangkok, Thailand) points out that the emergence of innovative technologies and their increased integration in education, especially after the COVID-19 pandemic, has popularized the concept of technological pedagogical content knowledge (TPACK) in the educational field. The aim of this study: Developing Technological Pedagogical Content Knowledge (TPACK) through Technology-Enhanced Content and Language-Integrated Learning (T-CLIL) Instruction was to determine whether technology-enhanced content and language-integrated learning (T-CLIL) instruction, which involves integrating technology into the CLIL approach that simultaneously focuses on non-language-related educational content and the target language, can improve the TPACK of preservice English teachers in tertiary education in Thailand.

Nardie L. J. A. Fanchamps (Fontys University of Applied Science, Netherlands and Zuyd University of Applied Science, Netherlands), Lou Slangen (Fontys University of Applied Science, Netherlands), Marcus Specht (Delft University of Technology, Netherlands) and Paul Hennissen (Fontys University of Applied Science, Netherlands and Zuyd University of Applied Science, Netherlands) then present: The Impact of SRA-Programming on Computational Thinking in a Visual Oriented Programming Environment. Visual programming environments are popular instruments in teaching Computational Thinking (CT) in schools today, they note, and applying Sense-Reason-Act (SRA) programming can influence the development of computational thinking when forcing pupils to anticipate the unforeseen in their computer programs. SRA-programming originates from the programming of tangible robots but can also be of equal value in visual programming with on-screen output. This research uses a pre-test post-test design that reveals significant differences in the development of computational thinking in two treatment conditions.

Trends and development in research on computational thinking by Mehmet Tekdal (University of Çukurova, Turkey) follows. This study revealed the change in research trends in the field of computational thinking (CT) in the last twelve years using bibliometric mapping analysis. The findings showed that research on CT is an emerging area that has grown exponentially since 2013 and literature has been produced as a result of national and international collaboration of researchers in several institutions and countries, mostly in the United States. It also showed that CT research is predominantly published in journals specializing in educational technology and feeds from information generated in education, computing, and social sciences and research topics contributing to the CT literature are grouped under three themes: Integrating CT into Science, Technology, Engineering, and Maths (STEM) education, experimental studies on assessing CT skills, and discussing definition of CT and CT skills. CT is an emerging discipline that will continue to evolve in the future.

Developing student connectedness under remote learning using digital resources: A systematic review is by Elizabeth Hehir, Marc Zeller, Joanna Luckhurst and Tara Chandler (University of Bolton, UK). They point out that online 
learning is negatively associated with student connectedness, and that due to the COVID-19 pandemic, Higher Education institutions have pivoted to blended and online learning. Consequently, Higher Education institutions have seen a shift in student connectedness resulting in loneliness, isolation, social and psychological distance. It is essential for teacher practitioners to respond with innovative digital learning resources that aim to develop student connectedness, and the systematic review aimed to explore the research question: what are the characteristics of effective digital teaching resources when the aim of the resource is to build student connectedness?

To complete this issue is English as a medium of instruction (EMI) in computing undergraduate programs by Munassir Alhamami (King Khalid University, Saudi Arabia). The author notes that the policy: English as a medium of instruction (EMI) in computing education, plays an important role in achieving the outcomes of computer science programs. This study examines the effects of Saudi Arabia's English as a medium of instruction (EMI) policy in undergraduate computer science programs at public universities. The study concluded that instructors need to differentiate between students' English proficiency and their knowledge of computer science when assessing students' work, and that policymakers should consider students' preferred language of instruction when designing computer science curricula. (This article has been updated.)

Articles in this issue come from researchers in: Afghanistan, Algeria, Australia, Bangladesh, Brazil, China, Czech Republic, UAE, Fifi, Finland, France, Greece, Hong Kong, India, Iraq, Israel, Italy, Jordan, Korea, Kyrgyz Republic, Malaysia, Mexico, Morocco, The Netherlands, New Zealand, North Cyprus, Oman, Pakistan, Palestine, Poland, Republic of Korea, Russia, Saudi Arabia, Sweden, Switzerland, Thailand, Tunisia, Turkey, UK, USA and Vietnam.

Dedicated, professional reviewers are an essential part of any research journal and EAIT is fortunate to have some excellent reviewers. We do, however, have a problem. We do not have enough reviewers! In 2020 we had over 1300 submissions to the journal (288 articles were published), and in the first eight months of 2021 we have received 1400 submissions. This means a huge effort for our present number of reviewers. We need more people to register as reviewers and we encourage readers to consider registering and inviting their colleagues also to register. To do this, go to the EAIT Editorial Manager (https://www.editorialmanager.com/eait/default.aspx) and click on Register Now.

Publisher's Note Springer Nature remains neutral with regard to jurisdictional claims in published maps and institutional affiliations. 